\title{
Uma Análise Quantitativa do Uso da Internet na Prática Pedagógica dos Professores das Escolas Municipais de Mossoró-RN
}

\author{
Rommel W. de Lima ${ }^{1}$, Stenio B. Fernandes ${ }^{2}$, Lindsay W. L. de Oliveira ${ }^{3}$ \\ ${ }^{1}$ Departamento de Informática - Universidade do Estado do Rio Grande do Norte \\ (UERN) - Mossoró, RN
}

${ }^{2}$ Secretaria de Estado da Educação e da Cultura - SEEC - RN

${ }^{3}$ Prefeitura Municipal de Mossoró - PMM

rommel.1ima@gmail.com,steniondre@hotmail.com, lindsaylopes2@yahoo.com.br

\begin{abstract}
This article aims to identify the use of Internet in teaching of primary school teachers. It is a quantitative study, where for the data collection was used a questionnaire prepared based on readings of the theoretical framework on the use of Internet in education. The questionnaire was conducted out in schools in the urban area of the municipality of Mossoró. The survey results show that teachers use the Internet and know of its importance in their pedagogical practice. The survey pointed out several advantages but also some difficulties with the use of this feature, even then, teachers use the Internet at school and at home. There was the need teacher to rethink and resignify their practice, considering that the teaching profession requires continuous training.
\end{abstract}

Resumo. Este artigo tem como objetivo identificar o uso da Internet na prática pedagógica dos professores do Ensino Fundamental. Trata-se de um estudo de natureza quantitativa, onde para a coleta dos dados foi utilizado um questionário, elaborado com base nas leituras do referencial teórico sobre o uso da Internet na educação. A aplicação do questionário foi realizada nas escolas da zona urbana do Município de Mossoró. Os resultados da pesquisa apontam que os professores utilizam a Internet e sabem da sua importância em seu fazer pedagógico. A pesquisa apontou várias vantagens como também algumas dificuldades para com o uso desse recurso, mesmo assim, os professores fazem uso da Internet na escola e em casa. Verificou-se a necessidade do professor repensar e (re)significar a sua prática, considerando que a profissão de professor requer formação continuada.

\section{Introdução}

Nos últimos anos as discussões sobre o uso das mídias é algo bastante presente no cotidiano das pessoas. A Internet, por exemplo, com suas facilidades de integrar recursos multimídia a um custo baixo, com rapidez, flexibilidade e interação até há 
pouco tempo impossível, vem se tornando uma ferramenta poderosa para o sistema educacional de ensino, tanto para os professores como para os alunos [MORÁN, 1999].

Segundo Morán (1999) a Internet é uma ferramenta que estimula a motivação dos alunos pela novidade e pelas possibilidades inesgotáveis de pesquisa que oferece. Essa motivação aumenta se o professor a faz em um clima de confiança, de abertura, de cordialidade com os alunos. Mais que a tecnologia, a comunicação autêntica do professor estabelece relações de confiança com os seus alunos, pelo equilíbrio, competência e simpatia com que atua.

A utilização da Internet pode oportunizar para os professores a inovação em sala de aula e o desenvolvimento de uma prática docente criativa e adequada às necessidades da atual sociedade [VALENTE, 2002]. Atualmente percebe-se que o professor não vive mais sem conexão com os meios de comunicações da informação, pois a tecnologia é uma forte aliada para o desenvolvimento da sua prática pedagógica como na sua vida diária.

Nesse sentido, este artigo tem como objetivo identificar o uso da Internet na prática pedagógica dos professores da rede municipal de ensino na cidade de MossoróRN. Para isso, estar organizado em mais quatro seções: a segunda seção aborda a metodologia da pesquisa, a terceira parte traz a fundamentação teórica, a quarta seção apresenta os resultados dos questionários e por fim, a quinta seção aponta a análises dos dados conseguidos e as considerações finais.

\section{Metodologia}

Este trabalho trata de uma pesquisa de natureza quantitativa, onde para a coleta dos dados foi desenvolvido um questionário de múltiplas escolhas. A aplicação do questionário foi realizado em 15 escolas, na zona urbana, da Rede Municipal de Ensino da Cidade de Mossoró-RN.

A elaboração do questionário foi desenvolvida através de uma pesquisa de caráter bibliográfico, com base teórica em Valente (2002), onde afirma que a maneira mais adequada de uso da Internet ainda depende da intenção pedagógica do professor.

O problema da pesquisa surgiu através das leituras do referencial teórico pesquisado nos sites: Google Acadêmico e www.br-ie.org (Site da Comissão Especial de Informática na Educação da Sociedade Brasileira de Computação). Nos trabalhos observados, foram analisados o uso da Internet na prática pedagógica, a importância do uso da Internet na sala de aula, a utilização do Laboratório de Informática como suporte pedagógico e a formação continuada para os professores sobre como usar os recursos tecnológicos, tanto na sua prática escolar como para uso pessoal.

Assim, foram desenvolvidas perguntas, ilustradas nas Figuras 1, com intuito de detectar se de fato os professores usam a Internet na sua prática pedagógica e de que forma. Também buscou identificar fatores que impeçam a não utilização desse recurso e de outros na sua instituição de ensino e no seu cotidiano.

\section{Fundamentação Teórica}

Para as discussões do referencial teórico sobre o uso da Internet foram abordadas as 
V Congresso Brasileiro de Informática na Educação (CBIE 2016)

Anais do XXII Workshop de Informática na Escola (WIE 2016)

contribuições de Morán (1999) e Souza (2008). Para discutir o uso da Internet como prática pedagógica na formação dos professores foram utilizados o aporte teórico de Valente (2002) e Garcia e Penteado (2005). Dai surgiu o interesse de pesquisar, juntos aos docentes da rede municipal de ensino, os seguintes temas: como os professores usam a Internet na sua prática pedagógica; como os professores utilizam os recursos de Informática como instrumento de mediação; perceber se a Internet é utilizada como recurso tecnológico na prática pedagógica dos professores e detectar a relevância do uso da Internet na formação dos professores.

Estudiosos como Garcia e Penteado (2005) destacaram em seu trabalho a importância da atuação do formador e da sua mediação no desenvolvimento das atividades de formação, especialmente quando envolvem a informática. É essa atuação que diferencia o uso dos recursos tecnológicos como atividade técnica das situações que levam os futuros professores a refletir sobre o que significa utilizar a informática para o aprendizado.

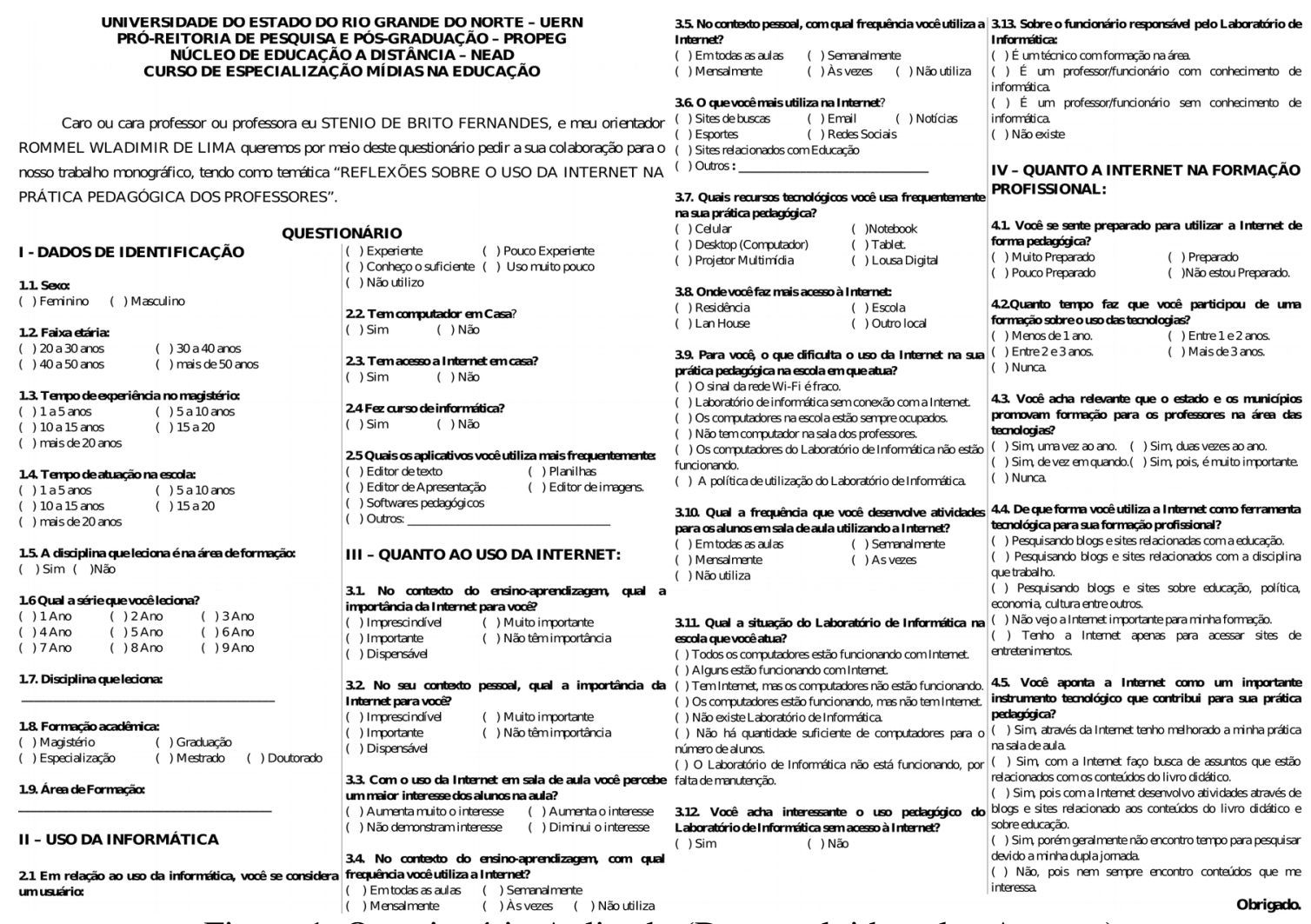

Figura 1: Questionário Aplicado (Desenvolvido pelos Autores)

Os questionários preenchidos foram digitalizados e os dados obtidos foram processados através do Software $\mathrm{R}^{1}$.

Garcia e Penteado (2005) salientam que é importante destacar a relevância dos espaços educacionais e principalmente os de formação docente, se constituam como

1 - R é um ambiente de software livre para computação estatística e gráfica (http://https://www.r-project.org/) 
lugar de acesso, produção e disseminação da informação. Assim, é preciso que as tecnologias estejam disponíveis aos futuros professores. Isso significa criar condições para que atuem como atores e não como meros espectadores.

Para Valente (2002), a formação do professor, para ser capaz de integrar a informática nas atividades que realiza em sala de aula, deve prover condições para ele construir conhecimento sobre as técnicas computacionais, entender por que e como integrar o computador na sua prática pedagógica e ser capaz de superar barreiras de ordem administrativa e pedagógica.

A tecnológica deve ser um fator comum entre o professor e seus alunos. Utilizar a informática em suas aulas é compartilhar com os alunos as experiências que já fazem parte do seu dia a dia. Essa proximidade poderia ser um facilitador nas interações entre professores e alunos.

Para Bruno e Ferreira Filho (2013), o professor precisa preparar o aluno para trabalhar com um universo tecnológico no qual ele mesmo ainda não domina totalmente esses recursos. O professor deve estar aberto a essas novas mudanças, principalmente no que se refere à sua nova postura, o de facilitador e mediador do processo de aprendizagem [GIRAFFA 2013].

Para que isso de fato aconteça, Garcia e Penteado (2005) acrescentam que a utilização da Internet na educação pode ser um caminho para novas formas de ensinar e aprender. É importante que os professores utilizem a Internet na sala de aula, pois, amplia as possibilidades de comunicação e de acesso às informações e permite que os alunos desenvolvam modos próprios de organizá-las e recuperá-las quando se fizer necessário.

Assim, os professores precisam de formação para lidarem com esses recursos tecnológicos em sala de aula e da importância destes para o desenvolvimento de uma educação de qualidade e, que é uma importante ferramenta no desenvolvimento do processo educativo. Observa-se também que a Internet e a educação estão presentes em todos os momentos e com a velocidade dos meios de comunicação de massas obrigam os professores a alterar o seu papel de transmissor e mediador de conhecimentos e passarem a dominar as novas tecnologias, no caso da Internet, para poderem acompanhar as mudanças do mundo.

Além dos trabalhos elencados anteriormente, alguns outros artigos analisados também abordam questões relacionadas com o tema: [Pinto and Passos 2014], [Assis and Alves 2012], [Pontes et al 2014], [Bruno and Ferreira Filho, 2013]. [Vieira and Baptista 2015], [Sorj and Lissovsky 2011], [Rocha et al 2007], [Marinho et al 2015], [Lago and Brito 2010], [Benedito and Moraes 2006], [Silva et al 2011], [Nascimento et al 2011], [Dal Forno and Melo 2013], [Oliveira el al 2011] e [Odorico et al 2012]. Com base nesses trabalhos, foi elaborado o questionário, ilustrado na Figura 1, que divide-se em quatro partes: Identificação, Uso da Informática, Uso da Internet e Internet na Formação Profissional.

\section{Resultados do Questionário}

$\mathrm{Na}$ pesquisa realizada foram entrevistados 103 (cento e três) professores em quinze 
V Congresso Brasileiro de Informática na Educação (CBIE 2016)

Anais do XXII Workshop de Informática na Escola (WIE 2016)

escolas na zona urbana da Rede Municipal de Ensino do Município de Mossoró-RN. Como já mencionado, o questionário aplicado dividia-se em quatro partes: Identificação, Uso da Informática, Uso da Internet e Internet na Formação Profissional. As próximas seções apresentam os resultados obtidos para cada uma das partes do questionário.

\subsection{Dados de Identificação}

Em relação aos dados de identificação, a Figura 2 ilustra os resultados obtidos após processamento no Software R, destacam-se:

- Em relação a questão de gênero, verificou-se que a grande maioria dos docentes, $68,93 \%$ são do sexo feminino e $31,07 \%$ são do sexo masculino.

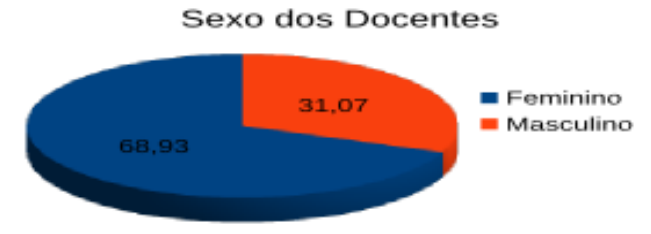

Tempo de Magistério

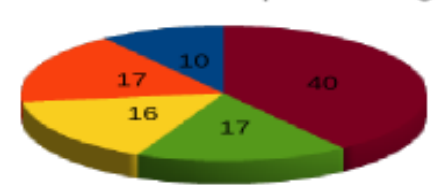

1 a 5 anos

= 5 a 10 anos

10 a 15 anos

$=15$ a 20 anos

- mais de 20 ano

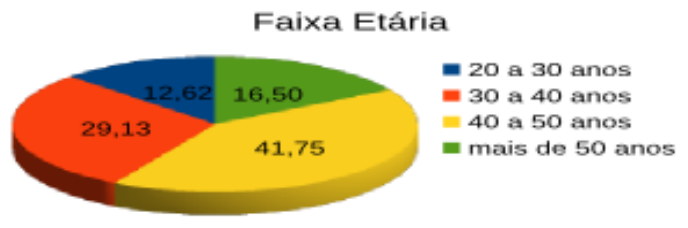

Tempo de Escola

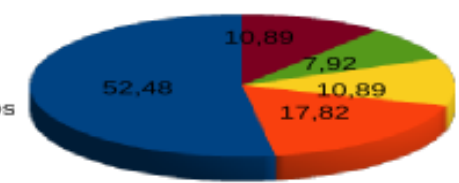

a 5 anos

- 5 a 10 anos

10 a 15 anos

- 15 a 20 anos

- mais de 20 anos

Leciona na Área de Formação

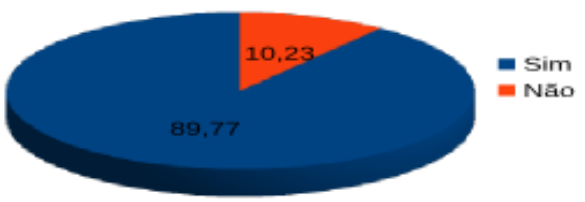

Titulaçăo

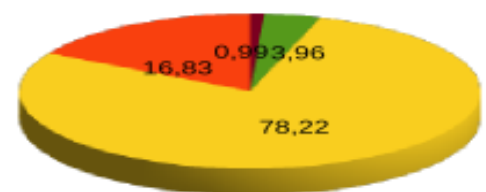

- Magistério

- Graduação

- Especializaçâo

- Mestrado

- Doutorado

Figura 2: Dados de Identificação

- Na faixa etária dos docentes, observou-se que $41,75 \%$ estão entre os 20 a 40 anos, outros $41,75 \%$ estão na faixa entre os 40 e 50 anos e 16,5\% possuem mais que 50 anos.

- Em relação ao tempo de magistério, observa-se que $40 \%$ possuem mais de 20 anos de experiência, 33\% possuem entre 10 e 20 anos de experiência e $27 \%$ possuem entre 1 e 10 anos de experiência no magistério.

- No que diz respeito a disciplina lecionada, observou-se que 89,77\% lecionam em sua área de formação e apenas $10,23 \%$ dos docentes estão fora de sua área de formação.

- No tocante a formação acadêmica, identificou-se que 78,22\% dos professores tem formação à nível de pós-graduação lato sensu, 4,95\% possuem pósgraduação stricto sensu e 16,83\% possuem apenas graduação.

\subsection{Uso da Informática}

$\mathrm{Na}$ segunda parte do questionário foram feitas perguntas para saber o domínio do professor no uso da informática. Em relação ao uso da informática pelo professor, obteve-se os seguintes dados, também ilustrados pela Figura 3:

- No que se refere ao uso da Informática: $25,74 \%$ dos professores se 
V Congresso Brasileiro de Informática na Educação (CBIE 2016)

Anais do XXII Workshop de Informática na Escola (WIE 2016)

consideram um usuário experiente, $27,72 \%$ se sentem pouco experiente, $36,63 \%$ se declararam com conhecimento suficiente e $8,91 \%$ dos professores acreditam que usam muito pouco a Informática.

- Em relação a possuir um computador em casa: 98,04\% confirmaram que sim, enquanto $1,96 \%$ afirmaram não ter.

- Quanto ao acesso à Internet em casa: 97,09\% afirmaram que possuem acesso à Internet e apenas 12,91\% informaram que não tem Internet em casa.

- No que diz respeito a fazer algum curso de informática: 82,52\% dos professores responderam que já fizeram, enquanto 17,48\% afirmaram que nunca participaram de um curso de Informática.

Tipo de Usuário em Relação ao Uso da Informática

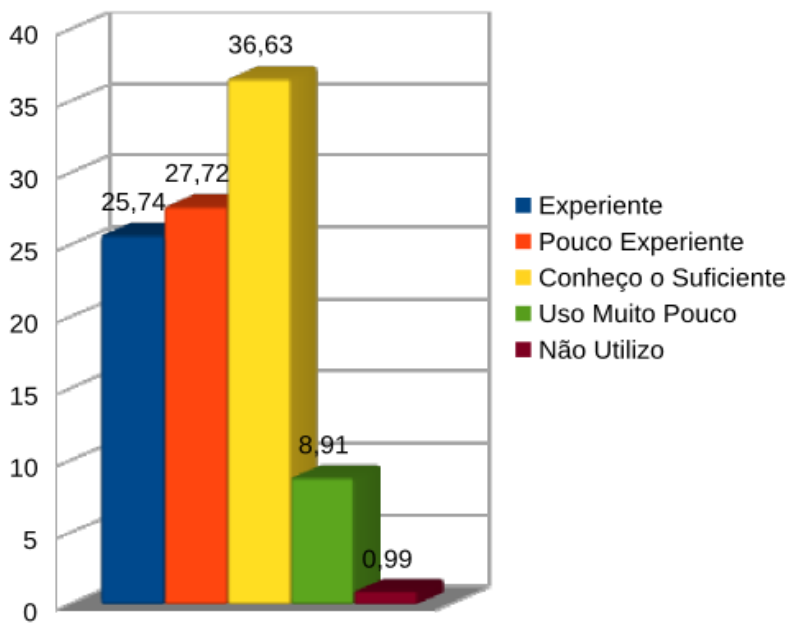

Possui Computador na Residência

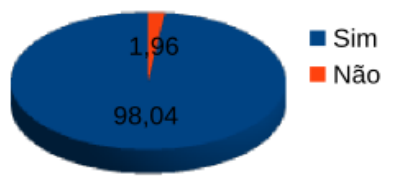

Acesso à Internet na Residência

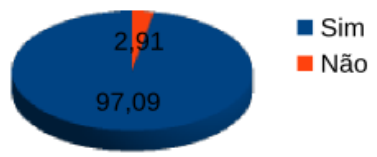

Fez Curso de Informática

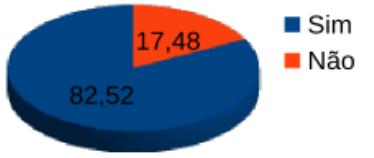

Figura 3: Dados relacionados ao Uso da Informática

\subsection{Uso da Internet}

A terceira parte do questionário abordava questões sobre o uso da Internet. Acerca do uso da Internet pelo professor, obteve-se os seguintes dados:

- Quando questionado sobre a importância da Internet para os professores no seu contexto profissional: $26,73 \%$ assumiram como imprescindível, $36,63 \%$ acharam muito importante e $35,64 \%$ importante.

- No que diz respeito da importância da Internet no contexto pessoal dos professores: 25,49\% reconheceram como imprescindível, 33,33\% acharam muito importante e $40,20 \%$ importante.

- Em relação ao uso da internet, em sala, aumentar o interesse dos alunos na aula: $43,30 \%$ confirmaram que aumenta muito o interesse e 55,67\% acharam que aumenta o interesse.

- No contexto do ensino-aprendizagem, com qual frequência os professores utilizam a Internet: apenas 5\% utilizam e todas as aulas, $31 \%$ responderam que usam semanalmente, $11 \%$ marcaram mensalmente, $45 \%$ confirmaram que às vezes e $8 \%$ responderam que não utiliza.

- Em relação ao uso da Internet no contexto pessoal: $25,26 \%$ dos professores responderam que utiliza todos os dias, $35,79 \%$ confirmaram que é semanalmente, $28,42 \%$ afirmaram que as vezes, $5,26 \%$ utilizam mensalmente 
e 5,26\% responderam que não utilizam.

- Em relação a onde mais acessa a Internet: 93,81\% apontaram sua residência, enquanto 1,03\% nas lan house, 2,06\% na escola e 3,09\% em outros locais.

- No que diz respeito as dificuldades que os professores têm de usar a Internet na sua prática pedagógica e na escola em que atuam: 24,72\% alegaram que o sinal da rede Wi-Fi é fraco, 6,74\% responderam que o laboratório de informática está sem conexão com a Internet, $7,87 \%$ afirmaram que os computadores na escola estão sempre ocupados, $24,72 \%$ confessaram que não tem computador na sala dos professores, 29,21\% afirmaram que os computadores do laboratório de informática não estão funcionando e 6,74\% apontaram a falta de política de utilização do laboratório de informática.

- No que diz respeito a frequência de atividades, utilizando a Internet, que os professores desenvolvem com os alunos em sala de aula, obteve-se os seguintes resultados: $8,33 \%$ responderam que realizam em todas as aulas, $28,13 \%$ afirmaram que usam semanalmente, $10,42 \%$ confirmaram que usam mensalmente, $39,58 \%$ responderam que às vezes e $13,54 \%$ assumiram que não utilizam.

- Sobre a situação do laboratório de informática nas escolas pesquisadas, foram obtidas as seguintes respostas: $9,68 \%$ responderam que todos os computadores estão funcionando com Internet, 8,6\% afirmaram que apenas alguns estão funcionando com Internet, $13,98 \%$ confirmaram que tem Internet, mas os computadores não estão funcionando, 5,38\% apontaram que os computadores estão funcionando, $10,75 \%$ afirmaram que não existe laboratório, 33,33\% alegaram que a quantidade de computadores é insuficiente para o número de alunos por turma e 18,28\% afirmaram que o laboratório de informática não está funcionando, por falta de manutenção.

- No tocante ao funcionário responsável pelo Laboratório de Informática: 15,38 informaram que é um técnico com formação na área, 37,36\% dos professores responderam ser um professor/funcionário com conhecimento de Informática, 3,3\% afirmaram que é um professor/funcionário sem conhecimento de informática e $43,96 \%$ confirmaram que não existe funcionário no laboratório de informática.

\subsection{Internet na Formação Profissional}

A última parte do questionário abordava a Internet e a formação profissional. Para essa parte, obteve-se os seguintes dados:

- No quesito sobre os professores se sentirem preparados para utilizarem a Internet de forma pedagógica: apenas $8,16 \%$ responderam que estão muito preparados, 29,59\% afirmaram que estão pouco preparados, 55,10\% apresentaram que estão preparados e $7,14 \%$ confirmaram que não estão preparados.

- Em relação ao tempo que faz da última capacitação sobre o uso das tecnologias: 26,26\% responderam que faz menos de 1 ano, 24,24\% confirmaram que faz entre 2 e 3 anos, 18,18\% afirmaram que faz entre 1 e 2 anos, 22,22\% responderam que faz mais de 3 anos e 9,09\% assumiram que nunca participaram. 
V Congresso Brasileiro de Informática na Educação (CBIE 2016)

Anais do XXII Workshop de Informática na Escola (WIE 2016)

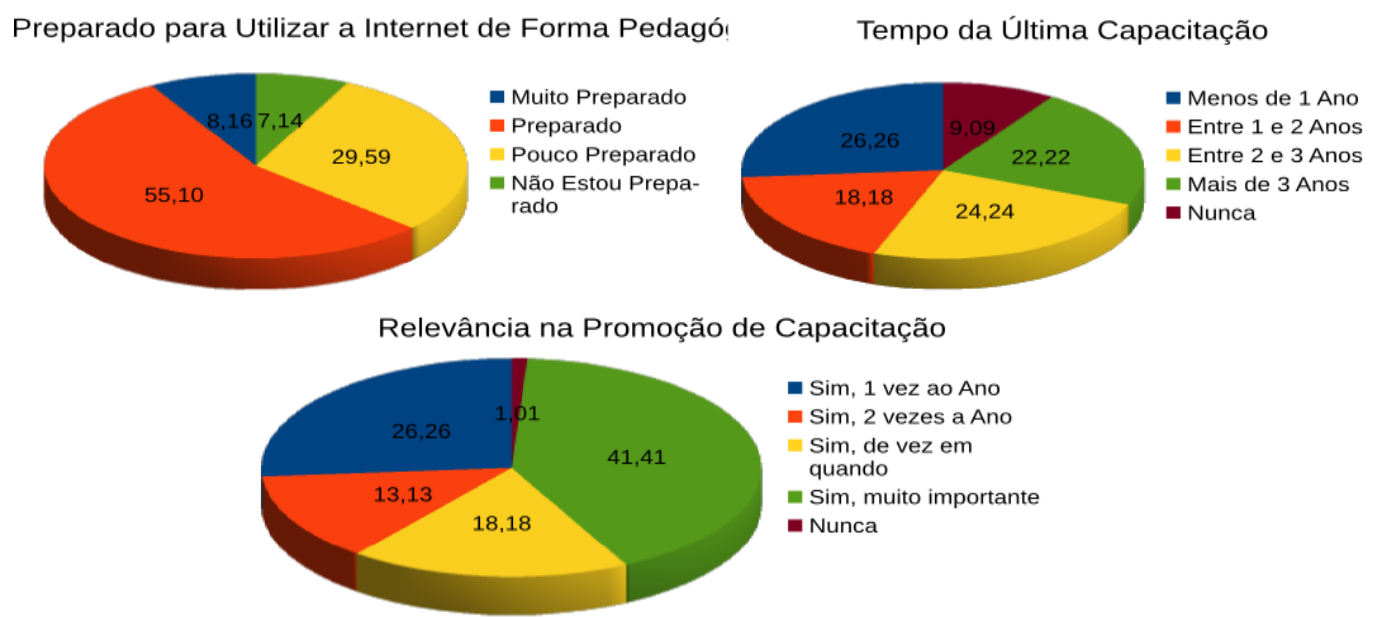

Figura 4: Dados Relacionados a Internet na Formação Profissional

- No que diz respeito a importância do Estado e Município promoverem capacitações na área das tecnologias: $26,27 \%$ pelo menos uma vez ao ano, $18,18 \%$ de vez em quando, $13,13 \%$ afirmaram que duas vezes ao ano, $41,41 \%$ apontaram apenas ser importante e apenas 1,01\% apontaram não ser importante.

\section{Análise e Considerações Finais}

A pesquisa mostrou uma maior presença do gênero feminino na docência escolar, com a grande maioria dos docentes lecionando em sua área de formação e um percentual muito superior com o título de especialista. Esses dados podem caracterizar um maior domínio de conteúdo por parte dos professores e que, de certa forma, buscam uma formação continuada e estão ampliando novos conhecimentos na oportunidade de reflexão e ação sobre a prática pedagógica, conforme aponta Lago e Brito (2010).

Em relação ao uso da informática a maioria dos professores possuem computador em casa com acesso à Internet. Verificou-se que grande parte dos professores dominam o uso da informática, em grande parte devido a realização de cursos técnicos de informática.

Segundo Bruno e Ferreira Filho (2013), o domínio das tecnologias de informação e comunicação é primordial, pois a partir disso, inicia-se o processo de desenvolvimento das atividades de ensino que se pretende aplicar, planejando uma aula dinâmica, criativa e segura.

Além disso, os resultados mostram que a formação dos docentes está no caminho certo. Segundo Assis e Alves (2012), a formação de professores é sempre um espaço de mobilização da experiência e de transformação da sua prática pedagógica, os professores necessitam buscar sempre novas informações e elaborar atividades que farão com que os alunos queiram sempre aprender e buscar novos conhecimentos.

Em relação ao uso da Internet, fica evidente que os professores enxergam a importância da rede mundial tanto no contexto profissional como pessoal. A grande 
V Congresso Brasileiro de Informática na Educação (CBIE 2016)

Anais do XXII Workshop de Informática na Escola (WIE 2016)

maioria dos professores fazem uso da Internet em seu cotidiano. Contudo, embora eles percebam o aumento do interesse do aluno na sala, quando da inserção pedagógica da Internet na aula, corroborando com Oliveira et al (2011), verificou-se que a grande maioria não faz uso desse recurso.

No questionário, essa deficiência no uso se apresenta principalmente pela falta de infraestrutura do laboratório de informática. $\mathrm{O}$ mesmo apontado por Benedito e Moraes (2006).

Por fim, a última parte do questionário fez referência a formação Profissional no uso da Internet. Verifica-se que a grande maioria dos professores se sentem preparado para usar, de forma pedagógica, a Internet em sala de aula. Além disso, embora um percentual significativo apontem para a importância da oferta de capacitações sobre o tema, observa-se que poucos se mantêm atualizados.

Nesse caso, é preciso que os professores tenham acesso à tecnologia informática, com possibilidades de interagir com esses recursos tecnológicas de forma diversificada e, também de discutir criticamente questões relacionadas com as transformações influenciadas pela informática, sobretudo nos estilos de conhecimento e nos padrões de interação social [Garcia and Penteado, 2005].

Os professores precisam ficar atentos às novas mudanças no cenário educacional e ampliar o conhecimento numa perspectiva reflexiva a partir da utilização das novas tecnologias como resultados concreto daquilo que é vivenciado na prática. Fica aqui a reflexão para a formação dos professores sobre o uso da Internet na sua prática pedagógica na busca de uma interação com os alunos, com os professores e com todos os sujeitos escolares.

\section{Referências}

Assis, D. R.; Alves, L. A. (2012) O impacto das redes sociais na relação professoraluno. http://www.docplayer.com.br, setembro.

Benedito, M. A., \& Moraes, M. C. (2006). A Tecnologia da Informação nas Escolas da Rede Municipal de Educação de Belo Horizonte. In Anais do Workshop de Informática na Escola (Vol. 1, No. 1).

Bruno, A. R., \& Ferreira Filho, L. N. (2013). Apropriações Das Tecnologias Digitais E Em Rede Por Professores: experiências nas escolas estaduais do Ceará, Brasil. Revista Eletrônica de Educação,7(2), 133-152.

Dal Forno, M. H., \& Melo, A. M. (2013). Um relato de experiencia de uso da informática na EMEB Eurípedes Brasil Milano. In Anais do Workshop de Informática na Escola (Vol. 1, No. 1, p. 425).

Garcia, T. M. R.; Penteado, M. G. (2005) Internet e formação de professores de matemática: desafios e possibilidades. GT: Educação Matemática / n.19.

Giraffa, L. M. (2013). Jornada nas Escol@ s: A nova geração de professores e alunos. Tecnologias, Sociedade e Conhecimento, 1(1), 100-118.

Lago, R. C., Brito, G. S. (2010). Educação continuada em Tecnologias de Informação e Comunicação: expectativas do professor. In Anais do Workshop de Informática na 
V Congresso Brasileiro de Informática na Educação (CBIE 2016)

Anais do XXII Workshop de Informática na Escola (WIE 2016)

Escola (Vol. 1, No. 1, pp. 1437-1440).

Marinho, A. R. S., da Silva Júnior, F. D. C., de Morais, P. S., \& Souza, G. (2015). Formação Inicial Docente Em Questão: O Pibid Na Licenciatura Em Informática. In Anais do Workshop de Informática na Escola (Vol. 21, No. 1, p. 370).

Morán, J. M. (1999) Internet no ensino. Artigo nacional - Internet no ensino. Comunicação \& Educação, São Paulo, 1141: 17 a 26, jan./abr.

Nascimento, K. A. S., Lima, M. S. S., Freire, R. S., \& de Castro Filho, J. A. (2011). Um olhar sobre as atividades dos Laboratórios de Informática Educativa das escolas municipais de Fortaleza. In Anais do Workshop de Informática na Escola (Vol. 1, No. 1, pp. 1256-1263).

Odorico, E. K., Nunes, D. M., Moreira, A., de Oliveira, H. M., \& Cardoso, A. (2012). Análise do não uso do laboratório de informática nas escolas públicas e estudo de caso. In Anais do Workshop de Informática na Escola (Vol. 1, No. 1).

Oliveira, A. M., Ludwig, L., \& Finco, M. D. (2011). Proposta Pedagógica do Uso das TICs como Recurso Interdisciplinar. In Anais do Workshop de Informática na Escola (Vol. 1, No. 1, pp. 1334-1341).

Pinto. M. L. G.; Passos, M. L. S. (2014) Reflexões sobre o uso da internet no fazer pedagógico dos professores do IFES Campus de Serra. XI ESUD.

Pontes, A. E., Pontes, S. G. R. and Santos, M. J. (2014). O uso do computador como ferramenta de mediação pedagógica no sistema municipal de educaçãoGOIATUBA-GOIÁS. The 4th International Congress on University-Industry Cooperation - Taubate, SP - Brazil

Rodrigues, C. S. (2011) A utilização da internet em sala de aula na escola Carlos Hugueney - Monografia apresentada ao Curso de Especialização em Informática na Educação - CUIABÁ - MT.

Silva, J. M., Lazzarotto, L. L., \& Tessari, R. (2011). O Ensino da Informática Básica para as Gerações X, Y e Z. In Anais do Workshop de Informática na Escola (Vol. 1, No. 1, pp. 1398-1401).

Sorj, B., \& Lissovsky, M. (2011). Internet nas escolas públicas: política além da política. Centro Edelstein de Pesquisas Sociais. Rio de Janeiro.

Souza, M. A. (2008) Material Didático Caderno Pedagógico Informática e Educação Especial desafio e possibilidade tecnológica. Universidade Tecnológica Federal do Paraná, Curitiba. http://www.diaadiaeducacao.pr.gov.br.

Valente, J. A. (2002). Uso da internet em sala de aula. Educar em revista, (19), 131-146.

Vieira, M., \& Baptista, B. (2015). A utilização das Tecnologias da Informação e Comunicação nos projetos educacionais interdisciplinares. In Anais do Workshop de Informática na Escola (Vol. 21, No. 1, p. 197). 